\title{
La irrupción de la cultura skater en el espacio público de Barcelona
}

\author{
Xavier Camino \\ Doctorat en Antropologia Urbana (URV) \\ Docent a l'Escola de Disseny i Enginyeria Elisava (UPF) \\ xavi.camino@hotmail.com
}

Resumen: Barcelona es escogida hoy por muchos skaters de todo el mundo como una ciudad de preferencia para vivir o visitar pues ofrece, casualmente gracias a su arquitectura y al diseño del espacio urbano, gran cantidad de espacios ideales para la práctica del skateboarding. De esta manera, muchos espacios urbanos son reinterpretados por skaters, lo que da lugar a nuevos usos y significados. A continuación presentamos los resultados de un estudio centrado en el desarrollo de esta práctica cultural en la ciudad de Barcelona. Partiendo de métodos tradicionales de la antropología como la observación distante y la observación participante, las entrevistas en profundidad, los relatos de vida y las fuentes documentales (bibliográfica, archivistica e internet), el investigador ha querido presentar una etnografía como estudio de caso para estimular el debate teórico en torno a temas como la cultura y la identidad en un contexto urbano marcado por la globalización.

Palabras clave: renovación urbana, skateboarding, espacio público, etnografía, campo social.

Abstract: Skaters from all over the world are currently choosing to live in or visit Barcelona because, by happy chance, its architecture and the design of its many urban spaces offer ideal opportunities to practice skateboarding. In this way, skaters are reinterpreting many urban spaces and giving them new uses and meanings. This article presents the results of a study on the nature of this cultural practice in Barcelona. The author bas used traditional anthropological methods such as remote observation and participant observation, in-depth interviews, life stories and documentary sources (bibliographies, archives and the internet). The aim has been to encourage theoretical debate about subjects such as culture and identity in a globalized urban context.

Keywords: urban regeneration, skateboarding, public space, ethnography, social ambit. 


\section{La ciudad de Barcelona como skateplaza}

A principios de la década de 2000 la ciudad de Barcelona empezó a ser reconocida por skaters de todo el mundo como un lugar de peregrinaje lleno de espacios y mobiliario magníficos para la práctica del monopatín. Revistas del sector y prensa local así lo reflejaban:

Mira, Barcelona es una gran ciudad y hay skaters de todo el mundo que vienen aquí (P. Domínguez, Kingpin Skateboarding Europa 1, 2002-03).

Las plazas duras y la tolerancia de la guardia urbana han convertido Barcelona en el destino preferido de los skaters de toda Europa (J. Puntí, El País, 19 de junio de 2003).

La transformación urbana que Barcelona experimentó durante el último cuarto del siglo xx dotó la ciudad de un paisaje urbano de gran calidad e inesperadamente idóneo para la práctica del streetstyle, ${ }^{1}$ la modalidad más difundida de skateboarding.

El gobierno de la ciudad dedicó grandes esfuerzos en proyectarse en la economía global. La entrada en la Comunidad Europea, así como la organización de grandes eventos como las Olimpiadas (1992) o el Fórum de las Culturas (2004), permitieron la entrada de importantes inversiones públicas y privadas destinadas a hacer la ciudad más competitiva, transformar su economía y adecuar el espacio urbano (Capel, 2005; Delgado, 2005, 2008; Borja, 2010).

En este proceso, la producción de espacio público ${ }^{2}$ fue uno de los principales instrumentos de desarrollo de la política urbana, sobre todo durante la primera etapa, marcada por una situación de crisis económica y entusiasmo democrático. Frente a la vieja ciudad gris del franquismo, la mejora del espacio público se instrumentalizó como una forma de incidir en la autoestima de la ciudad y sus ciudadanos (Cáceres, 1993; Borja, 2001, 2010; Capel, 2005). El espacio público se concibió como reflejo de la cultura mediterránea, como espacio de convivencia, ejemplo de la recuperación de la calle, la libertad y la democracia (Narotzky, 2007).

1. La práctica del streetstyle significa literalmente "estilo de calle" y consiste en la realización de maniobras con el monopatín utilizando el mobiliario urbano que ofrece la ciudad.

2. Durante la década de 1980 se hicieron unas 150 intervenciones de espacio público (Ayuntamiento de Barcelona, 1993); según Borja (2010), unas 300 intervenciones si sumamos los equipamientos. 
Urbanistas y arquitectos experimentaron con las últimas tendencias arquitectónicas, proyectando sus formas de ver el mundo en la producción del espacio urbano. Entre otras cosas, proliferaron las llamadas "plazas duras", espacios sin vegetación donde predominaba la estética vanguardista por encima de la función. La tendencia predominante consistía en espacios amplios y diáfanos, de superficies muy lisas con rampas, escalones, muros y bancos de distintas dimensiones, con materiales de gran calidad como el granito o el mármol. Asimismo, se hizo un gran esfuerzo por racionalizar y homogeneizar el mobiliario urbano. Se pretendía uniformizar el diseño urbano y contribuir a la construcción de una imagen de la ciudad asociada a la calidad del espacio (Cáceres, 1993). Las intervenciones no siempre fueron bien recibidas por el resto de ciudadanos, que querían espacios verdes o, al menos, más funcionales. El debate fue dilatado por la opinión pública a lo largo de las siguientes dos décadas (Moix, 1996).

Como resultado de este proceso, la ciudad de Barcelona destacó, muy por encima de otras ciudades renovadas, por la extensión, continuidad y uniformización de la calidad de su paisaje urbano. A finales de la década de 1990 Barcelona se había convertido, sin saberlo, en una de las mejores ciudades para la práctica del streetstyle: la ciudad skateplaza. ${ }^{3}$ Un skater de la época, entrevistado por la revista $U N O$, recuerda:

Solamente hacía tres años que se habían celebrado los Juegos Olímpicos y, como consecuencia de aquello, la ciudad entera experimentó un cambio; a mejor, evidentemente. Nuestra ciudad se tuvo que poner guapa para la fiesta y aparecieron spots [espacios patinables] nuevos. Recuerdo coger el metro y bajar en cualquier parada, explorar un poco y encontrar nuevos spots en cualquier barrio de Barcelona; lugares que ahora son famosos o spots que fueron famosos y ya han desaparecido (Juan La Torre, revista UNO, diciembre de 2009).

A principios de la década de 2000 muchas de las ciudades que durante la anterior década habían destacado como referentes internacionales para la práctica del streetstyle empezaron a perder popularidad, y la atención se dirigió al

3. Las skateplazas aparecieron a principios de la década de 2000 en el mundo de la construcción de skateparks, es decir, instalaciones dedicadas exclusivamente a la práctica del skateboarding. La diferencia entre los skateparks y las skateplazas consiste en que estas últimas están pensadas para la práctica del streetstyle. Por eso son diseñadas imitando la arquitectura y el mobiliario que existe en las calles y plazas de cualquier ciudad. 
descubrimiento de nuevas ciudades patinables. Frente a las persecuciones que el streetstyle experimentaba en otras ciudades, la ciudad de Barcelona apareció como un oasis, lleno de espacios por descubrir, libre de restricciones y con un clima mediterráneo favorable y una moneda que beneficiaba a los países del norte. La comercialización de reportajes de vídeos y revistas de skate sobre la ciudad, internet y el boca a boca entre los profesionales internacionales provocaron un progresivo aumento de la afluencia de skaters por las calles de la ciudad de Barcelona.

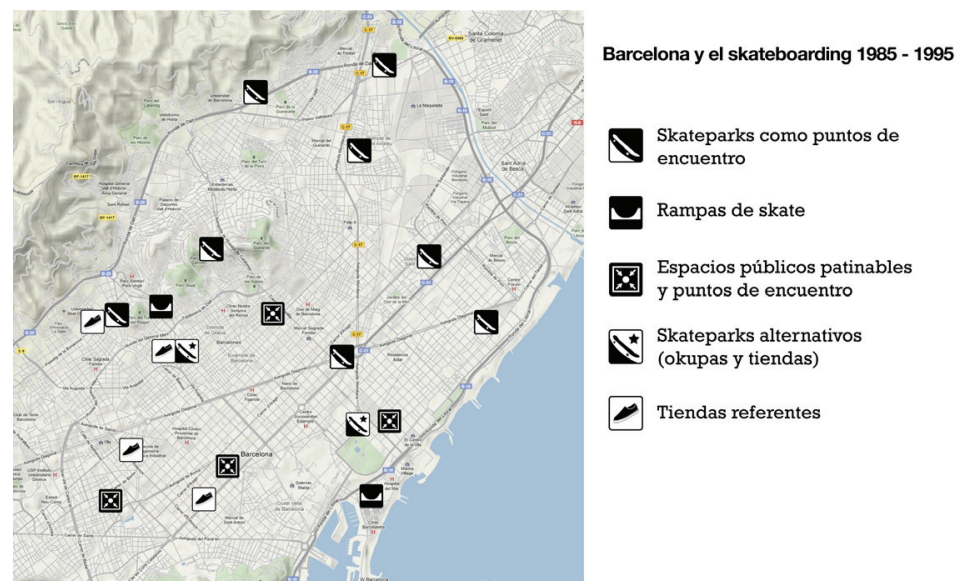

Fuente: X. Camino y M. Willcocks.

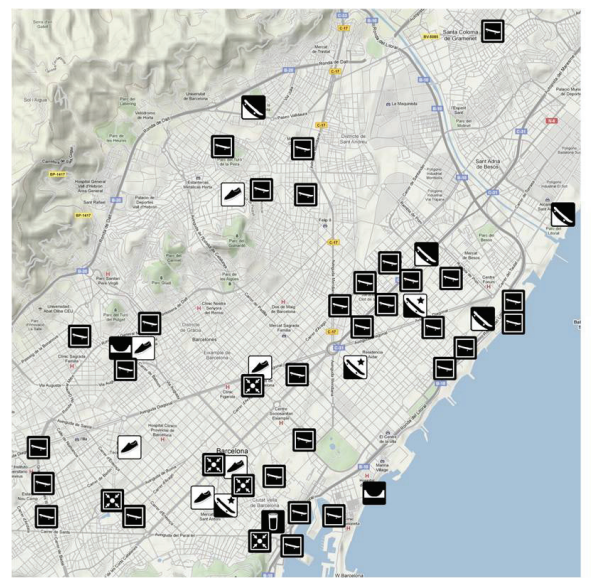

Barcelona y el skateboarding 1995 - 2010

Skateparks como puntos de encuentro

Rampas de skate

$\square$ Espacios públicos patinables internacionales y locales

Espacios públicos patinables y puntos de encuentro

^ Skateparks alternativos efímeros (okupas y tiendas)

Tiendas referentes

0 Bares como punto de encuentro

Fuente: X. Camino y M. Willcocks. 


\section{La cultura skater como objeto etnográfico}

A finales de 2002, cuando estaba terminando la licenciatura de Antropología, el espacio público seguía siendo uno de los temas centrales de debate para un importante número de académicos, intelectuales y organizaciones vecinales de Barcelona. Cuando acabé la carrera, me vi totalmente estimulado por el debate que había salpicado a un sector del Departamento de Antropología de la Universidad de Barcelona. En concreto, mi interés se fue orientando hacia cómo determinadas prácticas deportivas habían convertido algunos espacios públicos en importantes puntos de encuentro ${ }^{4}$ para sus practicantes. Además, en los últimos años se había producido un progresivo aumento del uso deportivo del espacio público. Según la "Encuesta sobre hábitos deportivos en España 2010" del CIS, en 2010 un 45\% de la población que practicaba deporte lo hacía en espacios abiertos y públicos, fuera de las instalaciones, en parques, calles, plazas, playas, montañas, etc., frente a un $19 \%$ en 1990 . Tal y como han demostrado diversos estudios, esas prácticas y sus espacios representan importantes fuentes de capital social de la ciudad (Maza, 2003, 2004; Camino, Maza, Puig, 2008).

Un día de primavera de 2003 me percaté del aumento inesperado de skaters en la plaza dels Àngels, en el núcleo urbano de la ciudad. Muchos de ellos eran turistas, extranjeros o autóctonos, profesionales o amateurs, visitantes esporádicos o habituales, de otros barrios o ciudades. Entonces no llegaban al medio centenar y, en la actualidad, hay días que superan el centenar. La plaza dels Àngels se ha convertido en un referente internacional.

Ahí está el inglés, el canadiense, el danés, el argentino, el brasileño, el norteamericano, el francés, el italiano, el español, el nativo y el extranjero, el aprendiz y el experto, el cauteloso y el osado, el que patina y al que se le patina. Vienen de todas partes del mundo, porque se corrió la voz y lo han leído en las revistas especializadas que patinar en la plaza del Macba es el paraíso del skate (M. García, El País, 2 de agosto de 2007).

Ante esta realidad me propuse desarrollar una etnografía centrada en el estudio del colectivo skater de la ciudad de Barcelona. ¿Dónde se practica skate en

\footnotetext{
4. Como punto de encuentro entiendo aquí todas aquellas actividades y espacios que ayudan o favorecen la interacción entre las personas y el desarrollo de las relaciones sociales (Maza, 2003, 2004; Camino, Maza y Puig, 2008). En los puntos de encuentro que genera el skateboarding se producen intercambios y conexiones, se construyen amistades y parejas, se generan entidades, negocios y empresas; en definitiva, toda una sociabilidad, una sociedad dentro de la sociedad (Camino, 2008).
} 
la ciudad?, ¿por qué Barcelona es un referente internacional del skateboarding?, ¿quién practica skate y por qué?, ¿qué significados y funciones tiene el skate para sus practicantes y el resto de la sociedad?, ¿cómo se producen y por qué los conflictos con otros usuarios?, ¿cómo se resuelven?, ¿existen experiencias de convivencia? o ¿los skateparks pueden apartar a los skaters de la calle? son algunas de las preguntas que me orientaron durante el proceso de investigación, entre 2003 y $2010{ }^{5}$

A continuación presento algunos de los resultados más relevantes de forma sintetizada. Primero expondré el proceso de emergencia y evolución de la cultura skater y sus significados; después reflexionaré en torno a algunas aportaciones del proceso metodológico; más tarde me detendré en explicar la perspectiva teórica adoptada y sus resultados; y, finalmente, analizaré el conflicto que el skateboarding plantea en la ciudad de Barcelona centrándome en algunos casos concretos.

\section{Orígenes y evolución de la cultura skater: un proceso reiterativo de integración-transgresión}

Los orígenes de la práctica del skateboarding debemos enmarcarlos en un contexto de crecimiento económico y de desarrollo del bienestar y del consumo en los EE. UU. durante las décadas de 1950 y 1960. El objeto skateboard entró a formar parte del estilo de vida hedonista de muchos surfistas de la costa de California a finales de la década de 1950 como una forma de entretenimiento cuando el mar se manifestaba impracticable. Con el objetivo de conseguir las mismas sensaciones que producía el surfing sobre una ola, trataban de emular sus movimientos sobre el skateboard descendiendo por calles o utilizando planos inclinados. Hasta que no se comercializaron a principios de la década de 1960, los surfistas construían sus propios skateboards con materiales reciclados. Así, en sus inicios, la práctica del skateboarding reproducía las imágenes culturales del surfing, por eso se le conocía popularmente como sidewalksurfing (surf de las aceras). La comercialización del skateboard durante la segunda mitad de la década de 1960 por EE. UU. y algunos países del norte de Europa favoreció su diferenciación como un campo autónomo del surfing. Sin embargo, a finales

5. Los resultados de esta fueron defendidos el 5 de mayo de 2012 como tesis doctoral en la Universitat Rovira i Virgili y puede ser consultada en <http://www.tesisenred.net/handle/10803/81714> (Camino, 2012). 
de la década de 1960 la crisis global que empezó a experimentar el sistema capitalista afectó drásticamente al mercado naciente del skateboarding. Muchas compañías acabaron cerrando después de perder importantes sumas de capital. Así, durante los años de mayor recesión económica, a principios de la década de 1970, la práctica del skateboarding quedó reducida a algunos puntos originales de la costa de California como Santa Cruz, La Jolla, San Fernando o Santa Mónica, principalmente (Borden, 2003).

No obstante, las innovaciones tecnológicas de la década de 1970, nuevamente en California, favorecieron un nuevo desarrollo del skateboarding. En concreto, la aparición de las ruedas de poliuretano supuso una revolución en este ámbito. No solo absorbían mejor las irregularidades del asfalto que las antiguas ruedas de arcilla o metal, sino que permitían coger mayor velocidad y hacer giros más bruscos y rápidos. Esto permitió trasladar la práctica a diversos terrenos urbanos.

El contexto de decadencia económica que experimentaban ciertos territorios influenció en la sociabilidad de aquella generación de skaters. Estos convirtieron espacios en ruinas, antiguos centros de ocio y consumo y hoteles abandonados en importantes puntos de encuentro y práctica del skate. Siguiendo las interpretaciones que Hebdige (2004) hizo sobre los movimientos culturales juveniles de la década de 1970, podemos decir que estos nuevos practicantes de skate que no vieron cumplirse las expectativas que se les habían creado durante su infancia adoptaron y desarrollaron valores transgresores.

A principios de la década de 1970, el skateboarding representaba, a los ojos de la cultura adulta dominante, un estilo de vida inmaduro, nada productivo y sin perspectivas de futuro. En cambio, para sus practicantes significaba una forma de vivir al margen de la sociedad a la que se resistían, utilizando espacios marginales o abandonados como lugares donde desarrollar su propia sociabilidad. Un claro ejemplo fue el estilo Dogtown, nombre que, con voluntad de diferenciarse, inventaron los skaters del sur de Santa Mónica (Los Ángeles) para designar su territorio, una zona socialmente degradada.

El fenómeno de la zona Dogtown explica la transformación de una experiencia local en un referente global gracias a la relevancia que ha adquirido el sistema de consumo en nuestra sociedad. A mediados de la década de 1970 las grandes compañías del momento que se fijaron en las posibilidades comerciales del nuevo estilo contrataron a skaters destacados del territorio Dogtown. 
Incluso la revista Skateboarder, que durante la década anterior había difundido el estilo hedonista Beach boys, difundió mediante textos de C. Stecyk e ilustraciones la vida skater en Dogtown. Su mercantilización mundial a lo largo de la segunda mitad de la década acabó por desactivar los significados transgresores y favoreció el surgimiento de nuevas modalidades prácticas deportivas, ${ }^{6}$ el ensayo de nuevas aplicaciones tecnológicas, diseños y materiales, así como el desarrollo de los skateparks y la formación de organizaciones deportivas.

Sin embargo, a finales de la década de 1970 el mercado del skateboarding volvió a experimentar una importante recesión que obligó a cerrar un importante número de empresas y skateparks (Borden, 2003; Mortimer, 2004). En todos los países donde se había desarrollado el negocio se produjo una importante reducción de consumidores y practicantes de skateboarding. La reestructuración que experimentaba la economía global favoreció el surgimiento de mercados nuevos asociados a nuevas actividades deportivas que empezaron a popularizarse y competían con un skateboarding en decadencia. Así que el snowboarding, el windsurfing, el bodyboarding, entre otras, sedujeron a nuevas generaciones y viejos skaters que abandonaron el skateboarding.

En este nuevo contexto, la recuperación y reinvención del skateboarding vino de la mano de las prácticas espaciales. A principios de la década de 1980 la aparición de una nueva maniobra desencadenó el desarrollo de una modalidad práctica que lo invadió todo: el streetstyle. Esta maniobra que se popularizó con el nombre de ollie ${ }^{7}$ permitía saltar bordillos y otros obstáculos urbanos sin demasiadas complicaciones. De este modo, esta maniobra favoreció el desarrollo del nuevo paradigma: inventar recorridos urbanos en los que cada bordillo, barandilla, rampa o escalón eran desafíos para desarrollar y probar nuevas maniobras.

Nuevamente en la costa de California, los jóvenes skaters que empezaron a experimentar en la calle con el mobiliario que se encontraban desarrollaron

6. El pool que se practicaba en piscinas vacías usando las curvas que la profundidad de la instalación ofrecía en la transición del plano a la pared; el downhill o descenso de colinas utilizando carreteras secundarias buscando alcanzar la máxima velocidad; el vertical en rampas y skateparks —instalaciones preparadas-; y el freestyle o estilo libre que consistía en realizar maniobras acrobáticas con el skate en un espacio liso casi sin desplazarse.

7. Esta maniobra nació a finales de la década de 1970, de la mano de Alan Gelfand's, cuando empezó a practicar saltos en las rampas sin sujetar la tabla con la mano. A principios de la década de 1980 algunos skaters de calle adaptaron aquella maniobra picando el tail (cola del skate) con el pie de atrás para hacer levantar el skate y arrastrarlo con el dorso del pie delantero (Borden, 2003; Mortimer, 2004; Mao y Fennetaux, 2004). 
nuevos significados transgresores. Sin embargo, el nuevo contexto, marcado por la globalización económica, la importancia de la información y los avances tecnológicos en medios de transporte y comunicación, favoreció una rápida comercialización del streetstyle. El aforismo Skate and destroy $y^{8}$ que difundió la revista Thrasher fue un claro ejemplo. Pronto el comercio asumió esos valores en el proceso de difusión del streetsyle.

Paralelamente, la reestructuración de la economía global comportó la renovación urbana de muchas ciudades norteamericanas en las que aparecía un diseño urbano favorable para el streetstyle. Una de las primeras ciudades que experimentó este proceso y se hizo famosa fue San Francisco con la renovación de la zona portuaria, el Embarcadero, un paseo al lado de la bahía de San Francisco de una gran calidad urbana.

La popularización del vídeo favoreció la difusión mundial de imágenes e historias de skaters de la zona de Los Ángeles y San Francisco. A principios de la década de 1990 estas ciudades empezaron a recibir una importante afluencia de skaters procedentes de todo el mundo. A mediados de la década la masificación de determinados espacios como el Embarcadero comportó la prohibición y persecución de la práctica del streestyle.

A principios de la década de 2000 la práctica del streetstyle experimentó una gran difusión y popularización en ciudades de todo el mundo, especialmente en las que habían experimentado una renovación urbana como Barcelona. La globalización económica, la emergencia de pequeñas compañías de skate en diversidad de países, la popularización del uso de internet y el vídeo doméstico, el crecimiento del turismo skater, etc., favorecieron la configuración de una red global de ciudades mitificadas para la práctica del streetstyle. Desde entonces, el viaje o el turismo se han incrementado en las trayectorias de vida de la mayoría de skaters. Por otro lado, su gran difusión mundial ${ }^{9}$ ha comportado una gran heterogeneidad de orígenes sociales y culturales entre los skaters. En la actualidad la edad de los practicantes de skateboarding oscila entre los 12 y los 40 años, y mayoritariamente son del género masculino. Por otro lado, la globalización ha favorecido la diversificación y especialización del mercado en los últimos

8. Este lema promovía entre los skaters el descubrimiento de la ciudad y la búsqueda de nuevos espacios y mobiliario urbano para la creación de nuevas y complicadas maniobras, aunque eso comportara la destrucción de mobiliario o la del propio skater.

9. Borden (2003) estimó que a principios de la década de 2000 había entre 10 y 20 millones de patinadores en todo el mundo. 
años, provocando la emergencia de nuevos estilos y modalidades prácticas, así como la recuperación de las tendencias de las décadas de 1960, 1970 o 1980.

A modo de conclusión, como hemos visto, la cultura skater emerge en California a principios de la década de 1960 y el sistema de consumo la expande por todo el mundo, de forma intermitente, a lo largo de la segunda mitad del siglo xx. Su evolución cultural y práctica siempre se ha producido bajo la influencia de los cambios que se han ido generando en California. Es decir, que siempre ha existido un cierto dominio de la producción de significados y prácticas desde California. Actualmente, aunque el proceso de globalización ha favorecido la aparición de colectivos de skaters referentes e importantes compañías competidoras en otros países, los Estados Unidos siguen siendo la principal potencia productora de prácticas, discursos y materiales.

Por otro lado, otro resultado interesante que nos ofrece la historia del skate trata sobre la relación que existe entre la evolución de los significados que produce el skate, su práctica y los cambios sociales y económicos globales. En general, se puede observar como la cultura skater experimenta un proceso reiterativo que va de la integración a la transgresión y vuelta a la integración, dependiendo del contexto económico y social del momento y, especialmente, influida por los procesos de mercantilización y deportivización que promueven las compañías comerciales. En la actualidad la transgresión-integración se dan simultáneamente y son utilizadas indistintamente por las compañías para promocionarse dentro del campo. Como ya observó Hebdige (2004), el sistema de consumo acaba integrando todos los significados subversivos que producen los jóvenes hasta convertirlos en artículos de consumo. Estos son nuevamente apropiados por los consumidores, contribuyendo a la configuración de sus identidades y adquiriendo nuevos significados y funciones. Siguiendo los análisis que autores como Castells (2003), Bauman $(2007,2006)$ o Baudrillard (2002) han hecho sobre la configuración de las identidades en la sociedad de consumo, podemos decir, finalmente, que el skateboarding no es más que una opción más, entre otras, en el mercado de las identidades. 


\section{Un terreno de análisis reticular y los roles contextuales del etnógrafo}

El trabajo de investigación que me planteaba el skateboarding en Barcelona añadía cierta dificultad a la hora de delimitar un terreno de análisis tal y como se hacía tradicionalmente desde la antropología. Las primeras prospecciones me ayudaron a identificar todos los espacios vinculados al mundo social del skate en Barcelona, y me di cuenta de que los skaters experimentaban una relación del espacio-tiempo muy diferente de la que había aprendido a abordar con las técnicas tradicionales de la antropología urbana. No podía delimitar el terreno de análisis a un barrio.

El colectivo skater presentaba una forma de habitar el territorio muy en sintonía con los cambios globales de finales del siglo xx. La introducción combinada y masiva de los transportes y de las telecomunicaciones a lo largo del siglo $\mathrm{xx}$ ha favorecido una progresiva transformación de las relaciones sociales al individualizarlas y separarlas de su entorno físico (Magrinyà, 2003). En la actualidad los individuos experimentan una alta movilidad y visitan diversos espacios para realizar sus actividades cotidianas (Muñoz, 2008).

La mayoría de skaters lo eran a tiempo parcial por cuanto practicaban skate y se relacionaban con otros skaters en determinados momentos del día. La identidad skater representaba solo una faceta del estilo de vida de cada aficionado, aunque los más jóvenes, el sistema de consumo y la publicidad se empeñaran en presentar el skate como una identidad inalterable. Y lo más importante, aunque la mayoría de skaters solía utilizar habitualmente un espacio cercano a su lugar de residencia como punto de encuentro entre sus amigos, las relaciones sociales que establecían con el skate se extendían más allá de su barrio y, a menudo, más allá de la ciudad. La gran movilidad que experimentaban para encontrarse con sus amigos y conocidos y practicar skate contribuía al dominio que solían tener de una gran extensión territorial y diversidad de puntos de encuentro. Por otro lado, la mayoría de estos puntos de encuentro se configuraban de una forma totalmente desvinculada del contexto de barrio donde se encontraban ubicados, aunque con estrecha relación con otros puntos de encuentro ubicados en otros barrios y ciudades. La cosa se complicó cuando identifiqué, durante el trabajo de campo, la existencia de conexiones que, a través del turismo, las acciones de 
las empresas transnacionales o la realidad virtual, superaban el área metropolitana hasta alcanzar una escala transnacional.

En este sentido, el terreno de análisis acabó conformando una especie de red o retícula de puntos de encuentro, espacios públicos y skateparks, locales okupados, tiendas y bares ubicados en diferentes barrios de la ciudad y otros municipios del área metropolitana. El campo social del skate me planteaba la necesidad de experimentar un campo de estudio discontinuo, reticular, formado por un conjunto de escenarios etnográficos distantes pero conectados.

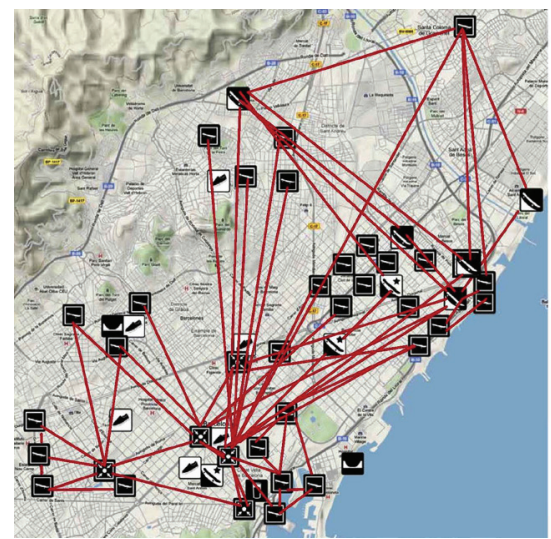

Barcelona y el skateboarding 1995 - 2010

Skateparks como puntos de

encuentro

Rampas de skate

$\square \quad \begin{aligned} & \text { Espacios públicos patinables } \\ & \text { internacionales y locales }\end{aligned}$

Espacios públicos patinables
y puntos de encuentro

1 Skateparks alternativos efímeros

(okupas y tiendas)

Tiendas referentes

[0 Bares como punto de

encuentro

Fuente: X. Camino y M. Willcocks.

Frente a este terreno de análisis, a lo largo de la investigación utilicé dos estrategias de recogida de información: la observación distante ${ }^{10}$ en espacios públicos y la observación participante con un grupo de skaters de Badalona. ${ }^{11}$

Aunque el etnógrafo suele considerar la observación participante como la técnica indispensable y la razón de ser de su etnografía, debo señalar que en mi caso la observación distante resultó ser una fuente de información muy productiva, sobre todo en relación con el abordaje de un terreno de análisis, el

10. Entendiendo como observación distante aquella que se centra en la recogida de información sin la necesidad de interactuación con las personas, aunque esta se puede dar de forma inesperada. En relación con la recogida de datos cuantitativos o notas descriptivas sobre el comportamiento de los sujetos en el espacio público fue muy útil.

11. El acceso al grupo de skaters de Badalona fue muy fortuito. Después de muchos esfuerzos dedicados a acceder a grupos del espacio público de Barcelona, surgió la oportunidad de acceder a este grupo gracias a contactos de mi propia red personal. A partir de este grupo fue mucho más fácil acceder a otros grupos conectados del resto de Cataluña, especialmente Barcelona. 
espacio público, muy extenso y reticular. Considero que este procedimiento ha influido de forma muy determinante en los resultados de esta investigación. La observación distante dio lugar a observaciones, charlas informales y entrevistas puntuales que, conjuntamente con las fuentes documentales, fueron muy útiles para el análisis de los procesos que experimentaron los puntos de encuentro, antes y durante mi trabajo de campo, así como las relaciones entre skaters, espacios, mobiliario, otros usuarios y la Administración.

Por otro lado, las experiencias etnográficas que compartí con muchos skaters me dieron acceso al análisis de las prácticas cotidianas del campo social y las trayectorias de vida de los skaters más próximos a lo largo de siete años. Pienso que la observación participante me permitió un nivel de comprensión del fenómeno que difícilmente hubiera sido alcanzado solamente con la observación distante. Hay que reconocer que la observación distante representaba, en un período inicial, una estrategia para activar la observación participante. Quiero decir con esto que, de alguna manera, la primera siempre ha estado al servicio de la segunda como una condición indispensable para construir la etnografía.

Finalmente, considero de especial interés reflexionar sobre los roles que he ido interpretando a lo largo de todo el trabajo de campo. Durante mi experiencia, los roles se sucedían como capas en el proceso de inmersión y comprensión del fenómeno. Pasaba de un rol a otro, dependiendo del contexto en el que me encontraba, dependiendo de la constelación de relaciones que se generaban. Así, experimenté como investigador etnógrafo, skater iniciado, amigo de skaters, miembro activo del Comité Català de Skate, intérprete de skaters para el Ayuntamiento, director de un equipo de investigación-acción, intermediariofacilitador entre Ayuntamiento y skaters, técnico del Ayuntamiento...

Esta versatilidad no debe ser entendida como un error en la aplicación de las técnicas tradicionales de la etnografía. Más bien representa una actitud abierta y flexible necesaria para profundizar en la comprensión del fenómeno que estudiamos desde la etnografía (Pujadas, Comas, Roca, 2004). Así, las relaciones que vamos estableciendo durante el trabajo de campo no son estáticas o inalterables, sino que representan procesos de interacción en los que los actores van experimentando cambios de roles que responden a cambios de contextos. Los roles que vamos asumiendo conscientemente nos acercan no solo a la comprensión de los distintos puntos de vista que coexisten en el campo social 
que estudiamos, sino también a los puntos de vista de otros campos en interacción como el del mismo investigador o el de los técnicos del Ayuntamiento. En otras palabras, la fluctuación del etnógrafo por los distintos contextos y roles ofrece una mirada transversal del campo de relaciones que se da durante la experiencia etnográfica.

\section{El campo social del skateboarding como perspectiva teórica}

Cuando me inicié en el trabajo de campo, el skateboarding se me presentaba con múltiples caras, a veces parecía un deporte, a veces un estilo de vida juvenil que transgredía un determinado orden social, a veces una moda pasajera, ocio y consumo, una práctica turística. $\mathrm{Al}$ mismo tiempo, la cultura skater mostraba una gran dependencia de otros ámbitos como la tecnología, la evolución del mercado o el urbanismo.

Por otro lado, los primeros contactos con skaters me indicaban que existían distintas formas de entender y practicar el skateboarding. No se trataba de un colectivo homogéneo cultural ni socialmente. Por ejemplo, había skaters que solo patinaban en instalaciones diseñadas para la práctica del skate, los skateparks, y criticaban la masificación de la plaza dels Àngels u otros escenarios internacionales. Otros decían que nunca pisarían un skatepark porque la esencia del skateboarding estaba en la calle y los skateparks eran como encierros.

Además, existía una gran diversidad de orígenes sociales entre los skaters que iba conociendo. Había arquitectos, licenciados en Educación Física, obreros de la construcción, carpinteros, abogados, mecánicos, ingenieros, camareros, informáticos, etc.

Ante esta realidad compleja, las nociones de campo social y habitus que desarrolló Bourdieu a lo largo de su obra fueron muy útiles para configurar una perspectiva teórica que me ayudara a abordar el análisis del fenómeno.

Según Bourdieu (1999), la complejidad de nuestra sociedad puede ser entendida como fruto de largos procesos de diferenciación. A partir de estos procesos la sociedad se ha ido descomponiendo en multitud de campos sociales, cada uno de los cuales responde a unos intereses concretos. Así, tenemos el campo de las artes, el campo literario, el político, el del deporte... Estos campos del espacio social establecen sus propias reglas, su propio lenguaje, sus propias 
formas de conocimiento y puntos de vista sobre el mundo, sus propios estilos de vida, mostrándose relativamente autónomos del resto de campos, aunque siempre en interacción. Son sociedades dentro de la sociedad.

Así, la imagen que me inspira esta idea de campo aplicada al caso del skate sería algo así:

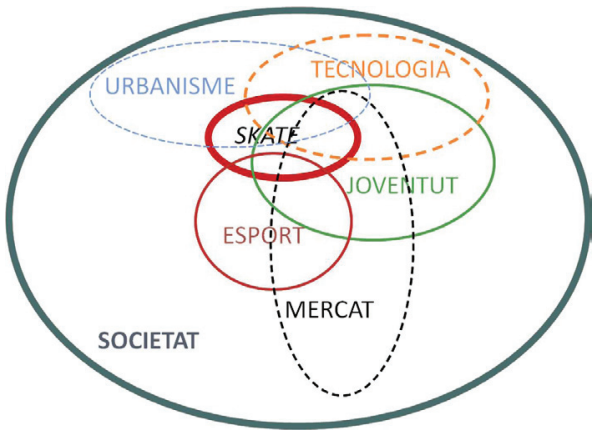

Fuente: X. Camino

El campo social del skate en el centro de nuestro interés, dentro de la sociedad, relativamente autónomo pero bajo la influencia y la interacción con otros campos como el deporte y la juventud como principios de diferenciación y otros campos que influyen como el mercado, el urbanismo o la tecnología.

Por otro lado, como ya he sugerido al principio de este apartado, la organización y estructuración de las distintas prácticas del skateboarding y sus significados generan diferentes discursos que surgen de la experiencia. Estos discursos se construyen a partir de las oposiciones que existen dentro del mundo social skater. El concepto de habitus puede sernos muy útil para entender estas diferencias dentro del colectivo skater. Bourdieu define el habitus como:

Principios generadores de prácticas distintas y distintivas [...], pero también son esquemas clasificatorios, principios de clasificación, principios de visión y de división (Bourdieu, 1997: 20).

El habitus es a la vez un sistema de esquemas de producción de prácticas y es a la vez un sistema de esquemas de percepción y apreciación de las prácticas. Y, en los dos casos, sus operaciones expresan la posición social en la cual se ha construido (Bourdieu, 1996: 134). 
En este sentido, podemos pensar esa diversidad de formas de entender y practicar el skate como los habitus específicos dentro del mundo social del skateboarding. Cómo se generaron estos habitus específicos tiene que ver con los procesos de diferenciación que se han dado en el skateboarding desde sus orígenes hasta la actualidad.

A partir de estas diferenciaciones internas, los campos se presentan como espacios simbólicos estructurados de posiciones, las de los habitus específicos. Estas posiciones se corresponden con las que adoptan los distintos agentes sociales o instituciones que forman parte interesada o implicada del campo. Esta estructura de posiciones se forma a partir de las relaciones de fuerza que se producen entre los agentes por la hegemonía del campo. La hegemonía consiste en adquirir el monopolio de la autoridad que otorga el poder de modificar o conservar la distribución del capital simbólico ${ }^{12}$ específico valorado en el campo: títulos, conocimientos, estilo de vida, dinero, contactos, adquisiciones profesionales, capacidad oratoria, origen social, presentación de uno mismo en público, etc. Así, la estructura de las posiciones de un campo no son estructuras fijas, las posiciones están siempre en movimiento, en interacción. En cada momento la estructura del campo se caracteriza por las relaciones de fuerza que se establecen a partir de las luchas simbólicas entre los distintos agentes o instituciones para defender la orientación hegemónica y la posición de poder que esta les brinda, o para intentar cambiar el orden establecido. Así pues, el punto de vista de una de las posiciones se erige, fruto de las luchas, como la institucionalización del campo social:

Cada campo es la institucionalización de un punto de vista en las cosas y en los habitus. El habitus específico, que se impone a los recién llegados como un derecho de entrada, no es otra cosa que un modo de pensamiento específico (un eidos), principio de una construcción específica de la realidad, fundado en una creencia prerreflexiva en el valor indiscutido de los instrumentos de construcción y de los objetos así construidos (ethos) (Bourdieu, 1999: 120).

12. El capital simbólico hace referencia al grado de eficacia que poseen los diferentes capitales (económico, cultural, social), como recursos reconocidos socialmente (de forma naturalizada), para reproducir satisfactoriamente un determinado estilo de vida que representa una posición dentro de la estructura social, legitimando así la relación de dominación de unos grupos sociales sobre otros. Se diría, en este sentido, que el capital simbólico designa el efecto de violencia simbólica de las diferentes formas de capital sobre las consciencias (Bourdieu, 1997, 1999, 2002). 
En el caso que nos ocupa, podemos afirmar que el punto de vista institucionalizado se corresponde con el streetstyle. En la actualidad los iniciados en el campo del skateboarding se interesan por la práctica del skate en la calle; con el paso del tiempo el conocimiento de la totalidad del campo social puede conllevar acercamientos, por parte de aquellos iniciados, a otras posiciones minoritarias, marginales o privilegiadas, a lo mejor más acordes con las especificidades de su habitus en otros campos de la sociedad, y dependiendo de los méritos o capitales simbólicos acumulados y heredados que tengan eficacia dentro del campo del skateboarding. Por ejemplo, son de especial valor simbólico los años que uno lleva patinando o haber formado parte de algún grupo histórico, haber visitado ciudades mitificadas, realizar las acrobacias más difíciles con el monopatín, conocer a profesionales conocidos, tener determinados patrocinadores, haber ganado campeonatos, ser un buen constructor de skateparks, tener conocimiento sobre la historia del skate, etc.

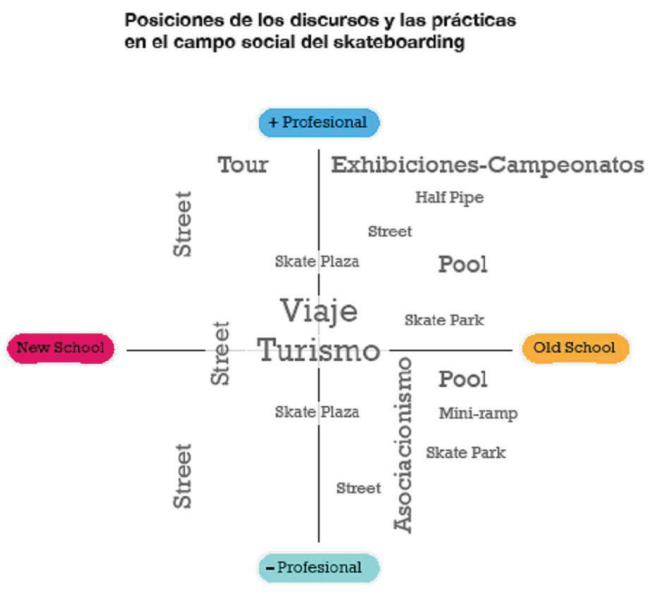

Fuente: X. Camino y M. Willcocks.

En esta gráfica, en la que se utilizan como ejes principales el perfil profesional del skater y los discursos antagónicos, puede verse como predomina el discurso new school, asociado a la práctica del streetstyle. Por otro lado, existen diferencias importantes entre las prácticas de los discursos: la old school, de perfil más profesional, queda asociada a actividades como las exhibiciones comerciales o los campeonatos deportivos, mientras que la new school tiende a la 
práctica de tours para realizar vídeos comerciales. Asimismo, es posible ver lo importante que es el viaje, aunque sea turístico, para visitar y practicar en espacios mitificados globalmente, o que las organizaciones deportivas representan un sector minoritario del perfil amateur y bastante alejado de las tendencias comerciales y profesionalizantes.

En Barcelona podemos identificar por lo menos los siguientes discursos o puntos de vista del mundo skater. Existe un sector minoritario que dedica grandes esfuerzos a deportivizar el skateboarding como una forma de conseguir respeto y reconocimiento social siguiendo los modelos tradicionales del deporte. Sergi Arenas, que ha participado activamente en la formación de la Asociación de Clubs Deportivos de Skate, dice:

L'esforç que invertim per aconseguir que l'skate sigui reconegut com un esport se sembla a l'esforç dels gestors d'instal+lacions, clubs y la federació d'atletisme per insistir que l'atletisme és un esport. Mentre la gran majoria de corredors no corren competitivament, no utilitzen les instal-lacions ni tampoc són socis de cap club ni estan federats. La nostra forma de pensar és una minoria entre els skaters, segur que representem menys del 10\% dels skaters (Sergi Arenas, entrevistado en diciembre de 2008).

Otro discurso más alternativo, opuesto tanto a los modelos deportivos o institucionales tradicionales como a los comerciales, queda bien representado en esta cita de un skater que participó en la construcción de un skatepark en unos almacenes okupados:

L'skatepark es va construir després de moltes promeses de l'Ajuntament que mai arribaven. Fa anys que sentim a parlar de les pistes que s'han de fer a Montjuïc, però res de res [...]. Era un servei necessari.. Això va ser una forma de passar de la burocràcia i anar per feina (Kiko Gago, Mike García, Jordi Paradelo, entrevistados por Albert Martínez para Directa núm. 28, 29 de noviembre de 2006).

El discurso más habitual y comercial es seguramente el asociado a la práctica del streetstyle, y puede verse reflejado en esta cita:

No sé, es algo diferente, no es como el futbol o un deporte. Tampoco lo entiendo como un deporte, es algo que te da libertad. No sé, vas a cualquier sitio y conoces gente con el patín, vas con tu patín y conoces gente, a mi me pasa eso (Julian Furones, entrevistado en enero de 2008). 
Si nos detenemos en el análisis de los relatos biográficos, el skateboarding ofrece otros significados y funciones. La mayoría de skaters entrevistados coinciden en que, cuando se iniciaron durante la adolescencia, el skate representó un lugar donde configurar su identidad, encontrar amistades y distinguirse del resto de la sociedad. Incluso ejerció una función preventiva en situaciones de riesgo de exclusión social. De mayores siguen diciendo que funciona como válvula de escape para ellos; sin embargo, la gran diferencia es que ahora el skate es, para la mayoría de los adultos, una faceta más, un deporte o un espacio de ocio donde encontrarse con amigos, etc.

Por otro lado, no podemos olvidar la gran influencia que ejercen en los relatos biográficos los orígenes sociales de cada skater. Las cinco trayectorias de vida reconstruidas en la tesis doctoral (Camino, 2012), teniendo en cuenta distintos orígenes sociales, muestran que el skateboarding es utilizado indistintamente por diversas clases sociales. De hecho, cada individuo tiende a utilizar el skate de acuerdo con el estilo de vida y la forma de ver el mundo de sus orígenes familiares, sociales y culturales. A modo de ejemplo, es posible ver las diferencias que existen en la forma de entender y practicar el skateboarding entre dos destacados informantes de esta investigación: Xavi y Sergi. El primero, que procede de una familia con una larga tradición en profesiones liberales, de clase media, estudió la licenciatura de Educación Física, trabaja de profesor en un instituto de secundaria y dedica grandes esfuerzos de su tiempo libre a institucionalizar el skateboarding. Entiende que el skateboarding debe organizarse utilizando los modelos tradicionales del deporte para conseguir reconocimiento institucional y social, así como para emanciparse de la gran dependencia que sufre de las grandes compañías comerciales. El segundo, en cambio, de orígenes más humildes, hijo de un padre inmigrante del sur de Andalucía y que consiguió un gran respeto a través de su oficio como carpintero-ebanista, utiliza el skateboarding como un medio para desarrollar su oficio y ser respetado como constructor de skateparks, incorporando incluso conocimientos y valores que heredó de su padre. 


\section{La práctica del skateboarding como oportunidad y conflicto en el espacio público}

El análisis de los procesos que han experimentado distintos espacios de Barcelona en relación con la práctica del skateboarding me ha llevado a concluir que el conflicto no se da tanto como la oportunidad. La opinión pública ha visibilizado el skate como un problema de convivencia. Pero en realidad el conflicto se produce en muy pocos espacios y son siempre los mismos; sin embargo, no se habla de la cantidad de espacios en los que el skate representa una oportunidad.

Los procesos de apropiación que los skaters llevan a cabo en diversos espacios urbanos pueden ser explicados a partir del tipo de relaciones que predominan en cada uno de ellos. Una forma que ayuda a explicar el tipo de relaciones que se dan en los espacios nos la proporciona el análisis de las relaciones de movilidad que predominan en ellos. Según Magrinyà (2003), existen cuatro tipos de relaciones de movilidad que pueden coexistir, aunque el predominio de uno de ellos puede determinar el carácter de un espacio. Esta tipología de relaciones de movilidad es el resultado de combinar, por una parte, el tipo de relaciones que se dan entre conocidos (homogéneas) o desconocidos (heterogéneas) y, por otra, si el espacio es un territorio con arraigo o no. Las relaciones de movilidad de vecindario se caracterizan por una relación estrecha del habitante con su territorio y por la homogeneidad en las relaciones. Un ejemplo paradigmático de este tipo de movilidad es el de un barrio obrero tradicional donde existe un solo grupo social arraigado al entorno físico. Las relaciones de movilidad dual se caracterizan, en cambio, por una relación estrecha con el territorio, en el que ya coexisten varios grupos sociales distintos, comunidades diferenciadas, y en él se establecen relaciones entre desconocidos (heterogéneas), además de las homogéneas dentro de cada grupo. Este tipo de movilidad es habitual en barrios donde conviven diversas comunidades inmigradas de diversos orígenes culturales. La introducción combinada y masiva de los transportes y de las telecomunicaciones genera una transformación profunda de las relaciones, al individualizarlas y separarlas de su entorno físico, y, por lo tanto, de su arraigo. De ahí surge, en primer lugar, la movilidad fragmentada. Esta se caracteriza porque los individuos mantienen relaciones con miembros de un mismo grupo (familia, trabajo, amigos de los hijos, etc.), sin que la posición en el espacio sea un elemento determinante. Un ejemplo de referencia es el centro comercial, 
adonde la gente acude en grupos bien diferenciados, estimulados por la actividad de consumo, sin experimentar ningún tipo de arraigo con el entorno físico y sin interactuar con los desconocidos. Paralelamente, surgen las relaciones asociadas a una movilidad de centralidad. Esta se manifiesta cuando los individuos buscan centros visibles y reconocibles del territorio, normalmente artificiales, que favorecen además el encuentro inesperado con otros grupos. En estos casos la interacción con desconocidos suele ser un estímulo para acudir. Tradicionalmente esto sucede durante el tiempo de ocio, a menudo durante el ocio nocturno, en las discotecas. Pero también sucede en espacios públicos como la plaza dels Àngels, donde es fácil acabar conversando con un desconocido en determinados momentos (Magrinyà, 2003).

\begin{tabular}{|c|c|c|c|}
\hline & $\begin{array}{l}\text { Relación } \\
\text { territorial }\end{array}$ & $\begin{array}{l}\text { Espacio de } \\
\text { relaciones } \\
\text { homogéneas } \\
\text { (interacción entre } \\
\text { conocidos) }\end{array}$ & $\begin{array}{l}\text { Espacio de } \\
\text { relaciones } \\
\text { heterogéneas } \\
\text { (interacción entre } \\
\text { desconocidos) } \\
\end{array}$ \\
\hline $\begin{array}{l}\text { Movilidad de } \\
\text { proximidad }\end{array}$ & $\begin{array}{l}\text { Arraigo } \\
\text { territorial }\end{array}$ & $\begin{array}{l}\text { Relaciones de } \\
\text { movilidad de } \\
\text { vecindario }\end{array}$ & $\begin{array}{l}\text { Relaciones de } \\
\text { movilidad } \\
\text { dual }\end{array}$ \\
\hline $\begin{array}{l}\text { Movilidad de } \\
\text { conexión }\end{array}$ & $\begin{array}{l}\text { Isomorfismo } \\
\text { espacial }\end{array}$ & $\begin{array}{l}\text { Relaciones de } \\
\text { movilidad } \\
\text { fragmentada }\end{array}$ & $\begin{array}{l}\text { Relaciones de } \\
\text { movilidad de } \\
\text { centralidad }\end{array}$ \\
\hline
\end{tabular}

Fuente: F. Magrinyà, 2003.

Podemos deducir, así pues, que los espacios donde predomina una combinación de relaciones de movilidad fragmentada y de centralidad donde los usuarios no interaccionan con el entorno se pueden convertir fácilmente en espacios frágiles, sin identidad, porque no hay apropiación del espacio (Magrinyà, 2003, 2008).

No obstante, el deporte puede ayudar a canalizar mejor las relaciones derivadas del predominio de la movilidad fragmentada o de centralidad en un espacio (Magrinyà, 2008). El deporte ayuda a convertir los espacios en puntos de encuentro porque fomenta la interacción entre desconocidos que practican un mismo deporte y favorece la generación de relaciones sociales. La emergen- 
cia de relaciones sociales ayuda a consolidar el uso cotidiano de los espacios y, consecuentemente, se inician procesos de apropiación del espacio y se establecen vínculos entre los usuarios y el espacio. Así, estos procesos de apropiación del deporte pueden convertir espacios residuales o inseguros, con poco arraigo territorial, en espacios más seguros, con identidad, y puntos de encuentro.

En el caso del skateboarding, el uso habitual que un grupo de skaters ejerce sobre un espacio, previamente fragilizado por el predomino de relaciones de movilidad fragmentada y sin relaciones de movilidad de vecindario, puede introducir los atributos propios del arraigo territorial al convertirlo en un punto de encuentro cotidiano para los skaters de la ciudad. Un proceso de apropiación de este tipo puede comportar, con el tiempo, que los skaters acaben transformando el espacio según sus intereses si no encuentran resistencias de otros grupos de usuarios. Además, con el tiempo, el reconocimiento del espacio entre los skaters puede introducir relaciones asociadas a la movilidad de centralidad cuando es visitado por turistas skaters. La plaza dels Països Catalans, los Jardins de les Tres Xemeneies o, incluso, los inicios de la plaza dels Àngels han experimentado procesos similares porque en ellos predominaba la movilidad fragmentada.

De hecho, el skateboarding parece consolidarse como punto de encuentro en espacios donde previamente hay una fragilización, donde no hay arraigo territorial. En cambio, donde previamente hay un predominio de las relaciones de movilidad vecinal, la aparición de skaters puede comportar situaciones conflictivas. El control que los vecinos ejercen sobre el espacio suele acabar comportando la expulsión de los skaters mediante diferentes procesos. El caso de la avenida Gaudí, donde a principios de la década de 1990 la afluencia de skaters comportó algunos conflictos y su consecuente expulsión, es un claro ejemplo.

Aunque este modelo de análisis nos muestra ya algunas tendencias generales de las relaciones que se producen entre el skateboarding y el territorio, debemos considerar otros factores que inciden en cada caso concreto. Cada espacio contiene unas condiciones previas que influyen en el curso de los procesos sociales que se dan en él. Las características físicas, la disposición del mobiliario, el contexto urbano, la gestión del espacio o la historia del espacio son algunas de estas condiciones.

Evidentemente, las características del espacio, su diseño y la disposición del mobiliario son condiciones previas indispensables para que el skateboarding 
pueda interesarse por su apropiación. Aun así, el contexto urbano del espacio puede facilitar o dificultar un proceso de apropiación skater. En el caso de la plaza dels Països Catalans se puede comprobar que la segregación espacial producida por el hecho de encontrarse rodeada de vías de circulación y la ausencia de fachadas de edificios residenciales y de otras actividades favorecen que la apropiación de los skaters sea profunda, permitiendo incluso que la transformen según sus intereses.

En la plaza Universitat, tan céntrica y con una intensa actividad comercial, se puede comprobar que la combinación de las movilidades de centralidad y fragmentada, conjuntamente con la segregación del espacio, delimitado y aislado por grandes vías de comunicación siempre llenas de vehículos, favorece la apropiación intermitente por parte de los skaters. Un espacio liso, amplio y de granito y un banco de piedra perfectamente pulido y larguísimo, ubicado en uno de los extremos, atraen a skaters de todas partes del mundo. Cuando en las horas punta la plaza es muy frecuentada por peatones que la cruzan, los skaters desaparecen.

Los espacios caracterizados por la continuidad de la trama urbana pueden añadir complicaciones a las relaciones entre skaters y otros usuarios. La plaza dels Àngels presenta una cierta complejidad. Requiere un análisis más profundo. En la actualidad confluyen diversos tipos de relaciones de movilidad, lo que genera algunos desencuentros, especialmente entre personas que establecen relaciones de movilidad fragmentada y personas que establecen relaciones de movilidad de centralidad; $y$, posteriormente, entre personas que establecen relaciones de movilidad de vecindario y skaters que establecen relaciones de movilidad de centralidad. No obstante, es evidente que la continuidad de la trama urbana, aunque es deseable, complica las relaciones. Si lo comparamos con el resto de espacios segregados que hemos explicado, resulta evidente que la segregación puede ser una ventaja para los skaters y la continuidad puede favorecer el conflicto entre vecinos y skaters por cuanto ayuda a tejer vínculos entre el territorio y los vecinos, al consolidar el arraigo territorial de estos y su voluntad de controlar el espacio.

Si comparamos la plaza dels Àngels y la plaza dels Països Catalans, podemos comprobar que la segregación espacial de la segunda, generada por las vías circundantes siempre llenas de tráfico, favorece que los flujos de peatones que pasan por allí lo hagan por los márgenes, dejando el espacio central libre para 
los skaters. En cambio, en la plaza dels Àngels la continuidad de la trama urbana y la centralidad de la plaza favorecen que los flujos de peatones del barrio crucen por el centro de esta, lo que comporta el desencuentro con los skaters.
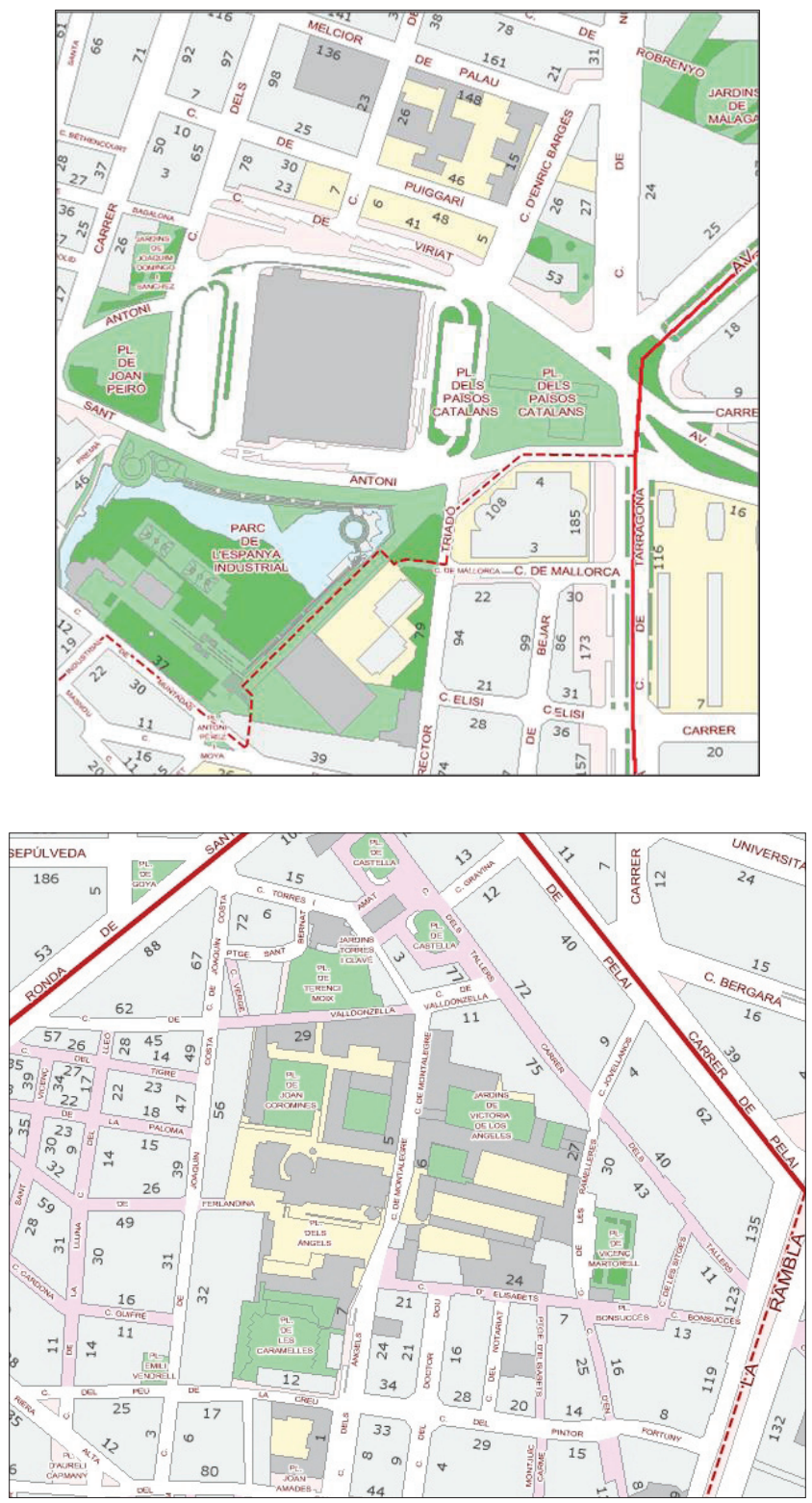
Finalmente, podemos resumir que los procesos de apropiación del skateboarding buscan espacios residuales, zonas de paso o periféricas, sin relaciones de movilidad de vecindario, y que con su práctica realizan una apropiación del espacio que antes no existía. Por ello, suelen aportar más aspectos positivos a las relaciones sociales que se dan en los espacios urbanos y no tanto complicaciones o relaciones conflictivas. De hecho, el skateboarding ha comportado problemas de convivencia en la ciudad de Barcelona en momentos y espacios muy concretos como la avenida Gaudí, el skatepark del Turó Park o la plaza dels Àngels. El modelo de análisis de las relaciones de movilidad y las condiciones previas que presentan los espacios muestran que la práctica del skateboarding contribuye más a convertirlos en puntos de encuentro y no tanto a fragilizarlos o a generar conflictos.

\section{Conclusiones}

La historia del skateboarding nos muestra la gran dependencia que esta práctica cultural tiene del sistema de consumo. En este sentido, podemos concluir que el skateboarding, a lo largo de su existencia, funciona como un modelo de distinción social que el sistema de consumo ofrece a los jóvenes como imagen y práctica transgresora. Pero su mercantilización y deportivización desactivan con frecuencia esa transgresión, que acaba siendo solo una apariencia.

Por otro lado, las trayectorias de vida de la mayoría de los skaters que han participado en esta investigación, así como la etnografía de las organizaciones del campo social, muestran como la práctica del skateboarding representa también un mecanismo de integración social y funciona como preventivo social ante posibles situaciones de exclusión en la medida en que todos los puntos de encuentro que configuran el campo social representan una fuente de identidad, de capital social y de válvula de escape para sus practicantes.

En relación con el espacio público, el skateboarding y otros deportes que se practican en el espacio urbano de forma espontánea pueden ser interpretados, después de los análisis de casos aportados, como oportunidades y no tanto como problemas de convivencia si entendemos que ayudan a convertir espacios fragilizados por las relaciones de movilidad fragmentada, espacios inseguros o marginales, en espacios seguros, en puntos de encuentro y en fuentes de capital social. 
Finalmente, cabe decir que los resultados de esta investigación pretenden aportar, a través del caso del skateboarding, una etnografía urbana marcada por un contexto de globalización. En este sentido, pretende abrir también la reflexión de cómo aplicamos los métodos tradicionales de la etnografía a fenómenos culturales que ya no se pueden delimitar a una escala territorial de barrio.

\section{Bibliografía}

Ajuntament de Barcelona (1993). Barcelona, espacio público. Barcelona: Ajuntament de Barcelona.

- (1999). Urbanismo en Barcelona. Barcelona: Ajuntament de Barcelona.

- (2005). "Mesures per a fomentar i garantir la convivencia ciutadana en l'espai públic de Barcelona”, en Ordenances Municipals de Barcelona. Barcelona: Ajuntament de Barcelona.

Baudrillard, J. (2007). La sociedad de consumo. Sus mitos, sus estructuras. Madrid: Editorial Siglo XXI.

Baumann, Z. (2006). La comunidad. En busca de seguridad en un mundo hostil. Madrid: Editorial Siglo XXI.

- (2007). Vida de consumo. Buenos Aires: Editorial FCE.

Borden, I. (2003). Skateboarding, space and the city. Oxford: Berg.

Borja, J. y Muxí, Z. (2001). L'espai públic: ciutat i ciutadania. Barcelona: Diputació de Barcelona.

Borja, J. (2010). Llums i ombres de l'urbanisme de Barcelona. Barcelona: Editorial Empúries.

Bourdieu, P. (1996). Cosas dichas. Barcelona: Gedisa.

- (1997). Razones prácticas. Sobre la teoría de la acción. Barcelona: Anagrama.

- (1999). Meditaciones pascalianas. Barcelona: Anagrama.

- (2000). La dominación masculina. Barcelona: Anagrama.

- (2002). La distinción. Criterio y bases sociales del gusto. México D.F.: Taurus.

Cáceres, R. (1993). "El diseño del espacio público”, en Ajuntament de Barcelona, Barcelona, espacio público. Barcelona: Ajuntament de Barcelona.

Camino, X. (2012). Estudio cultural del skateboarding en Barcelona (19752010). Tesis doctoral inédita, dirigida por Joan Josep Pujadas y Gaspar Maza. Universitat Rovira i Virgili (Tarragona), Departamento de Antro- 
pología, Filosofía y Trabajo Social. <http://www.tesisenred.net/handle/10803/81714>

- (2008). "Reinterpretando la ciudad: la cultura skater y las calles de Barcelona”, en N. Puig y G. Maza (coords.), El deporte en los espacios públicos urbanos de Barcelona. Monográfico de Apunts. Educación Física y Deportes (91), Barcelona.

Camino, X.; Maza, G. y Puig, N. (2008). "Redes sociales y deporte en los espacios públicos de Barcelona”, en N. Puig y G. Maza (coords.), El deporte en los espacios públicos urbanos de Barcelona. Monográfico de Apunts. Educación Física y Deportes (91), Barcelona.

CAPel, H. (2005). El modelo Barcelona: un examen crítico. Barcelona: Ediciones del Serbal.

Castells, M. (2003). La era de la información. Vol. II “El poder de la identidad". Madrid: Editorial Alianza.

Delgado, M. (2005). Elogi del vianant. Del model Barcelona a la Barcelona real. Barcelona: 1984 edicions.

- (2008). La ciudad mentirosa. Fraude y miseria del "modelo Barcelona". Barcelona: Editorial Catarata.

García, M. (2007)."El paraíso del skate”, en El País, 2 de agosto de 2007.

García Ferrando, M. (2010)."Encuesta sobre hábitos deportivos de los españoles, 2010". Madrid: Consejo Superior de Deportes, Centro de Investigaciones Sociológicas.

Hebdige, D. (2004). Subcultura. El significado del estilo. Barcelona: Paidós.

Magrinyà, F. (2003). "Hacia una relectura de los espacios públicos desde la posmodernidad. El ejemplo del Raval de Barcelona”, en R. Parramon, J. Díez y N. Enguita et alii, Proyectos de intervención crítica e interacción social en el espacio público. Madrid: Editorial Injuve.

- (2008). "Urbanismo y deporteः análisis de las prácticas deportivas informales en el espacio público de Barcelona”, en N. Puig y G. Maza (coords.), El deporte en los espacios públicos urbanos de Barcelona. Monográfico de Apunts. Educación Física y Deportes (91), Barcelona.

Maza, G. (2003). “El deporte del bar”, en F. X. Medina y R. Sánchez (eds.), Culturas en juego. Ensayos de antropología del deporte en España. Barcelona: Icària \& ICA. 
- (2004). "El capital social del deporte”, en T. Lleixa y S. Soler (comps.), Actividad física y deporte en las sociedades multiculturales. ¿Inclusión o segregación? Barcelona: Editorial Ice-Horsori.

Morx, Ll. (1996). La ciudad de los arquitectos. Barcelona: Anagrama.

Mortimer, S. (2004). Tony Hawk. Ocupación: skateboarder. Barcelona: Reservoir Books Mondadori.

Muñoz, F. (2008). Urbanalización. Paisajes comunes, lugares globales. Barcelona: Editorial Gustavo Gil.

Narotzky, V. (2007). La Barcelona del diseño. Barcelona: Santa \& Cole.

Pujadas, J. J. (coord.); Comas, D. y Roca, J. (2004). Etnografia. Barcelona: Editorial UOC.

Puntí, J. (2003). “La Meca del monopatín”, en El País, 19 de junio de 2003. 